\title{
STD trotz sexueller Abstinenz? Hier flunkert jemand!
}

Ein Eckstein im Bereich der sexualmedizinischen Forschung ist die Selbstauskunft der Studienteilnehmer über ihr Sexualleben. Doch ist auf solche Angaben tatsächlich Verlass? Zumindest bei jungen Erwachsenen scheint dies nicht immer der Fall zu sein, wie eine aktuelle, in der Zeitschrift Pediatrics veröffentlichte, USamerikanische Studie zeigt [1].

Stimmen die Angaben von jungen Erwachsenen bezüglich ihres Sexuallebens mit den Ergebnissen von Labortests auf nicht virale sexuell übertragbare Erkrankungen (STD) überein? Dieser Frage gingen US-amerikanische Wissenschaftler kürzlich nach. Dabei nutzten sie Daten aus der National Longitudinal Study of Adolescent Health (Add Health), an der eine repräsentative Auswahl junger US-amerikanischer Erwachsener $(n=14.012)$ teilgenommen hat - insgesamt 7497 Frauen und 6636 Männer im Alter von Anfang bis Mitte 20.

Die Studienteilnehmer beantworteten einen Fragebogen bezüglich ihres Sexuallebens innerhalb der letzten zwölf Monate und gaben Urinproben ab, um auf Chlamydia trachomatis und Neisseria gonorrhoeae getestet zu werden. Außerdem wurde ein PCR-Test (polymerase chain reaction) durchgeQuelle: Marion Weber, SpringerMedizin.de fassen.

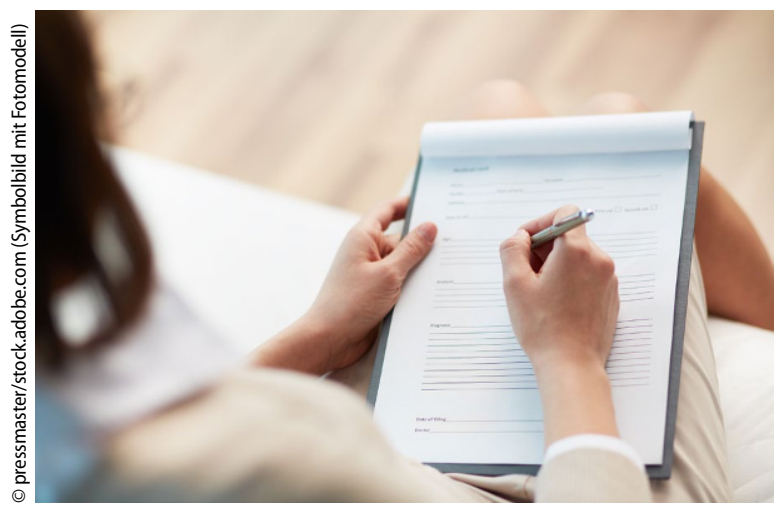

Abb. 1 A Rund 10\% der jungen Erwachsenen mit positivem Laborergebnis gaben an, im vergangenen Jahr keinen Geschlechtsverkehr gehabt zu haben
Routinemäßiges Screening nötig? $6 \%$ der getesteten US-amerikanischen jungen Frauen und Männer hatten ein positives Testergebnis für eine der drei STDs - Gonorrhö, Chlamydien oder Trichomoniasis. 79,7\% der Studienteilnehmer berichteten, im vergangenen Jahr Geschlechtsverkehr gehabt zu haben. $36 \%$ mehr Frauen als Männer hatten eine STD.

》) $6 \%$ der getesteten jungen Frauen und Männer hatten ein positives Testergebnis für eine der drei STDs

Es zeigte sich außerdem ein signifikanter Zusammenhang zwischen einem positiven STD-Test und der Auskunft, innerhalb der letzten zwölf Monate Sex gehabt zu haben, aber die Wahrscheinlichkeit für ein positives Laborergebnis betrug nur geringfügig mehr als das Doppelte (Odds Ratio: 2,11; $95 \%$-Konfidenzintervall: 2,0972,122). 10,5\% der jungen Erwachsenen mit positivem Laborergebnis hatten angegeben, im vergangenen Jahr keinen Geschlechtsverkehr gehabt zu haben, die Hälfte davon berichtete sogar, noch nie Sex gehabt zu haben (- Abb. 1).

Die Studienautoren werteten diese Fälle als Diskrepanz zwischen STD-Test und Selbstauskunft, obwohl sie einräumten, dass die Angabe im letzten Jahr keinen Sex gehabt zu haben auch bei einem positiven STD-Test korrekt sein könnte, wenn die Infektion schon länger als ein Jahr bestanden hatte. Einen signifikanten Zusammenhang zwischen diskrepanten Aussagen und soziodemografischen Faktoren wie Geschlecht, Alter und Bildungsstand gab es nicht.

Um die STD-Häufigkeit bei jungen Menschen zu reduzieren, müsste demnach eine routinemäßiges STDScreening erfolgen, so die Studienautoren. Sie schlussfolgern: „Unsere Ergebnisse machen deutlich, dass es wahrscheinlich eine große Zahl STDs geben wird, die undiagnostiziert und unbehandelt bleiben und an zukünftige Sexualpartner weitergegeben werden, wenn Mediziner nicht alle jungen Menschen testen." Außerdem warnen die Autoren aufgrund ihrer Analyse davor, Selbstauskünfte über die sexuelle Aktivität als Marker für das STD-Erkrankungsrisiko zu nutzen. Dies könnte zu problematischen Ungenauigkeiten führen.

\section{Literatur}

1. DiClemente R et al (2010) Association between sexually transmitted diseases and young adults' self-reported abstinence. Pediatrics 127: 208-213

hautnah $2018 \cdot 17: 48$ https://doi.org/10.1007/s12326018-0277-5

(c) Springer-Verlag GmbH Austria, ein Teil von Springer Nature 2018 